Em sua passagem pelos diversos annos do curso distinguiu-se sempre pelo seu vigor intellectual e pela sua dedicação á sciencia.

Como amigo dedicado que era, nelle podiamos confiar com segurança, porque João Eduardo era leal e de uma firmeza de caracter inquebrantavel.

Companheiro, nunca o vimos acabrunhado e, na escola ou fóra della, tendo á frente qualquer obstaculo, vimo-lo marchar seguro e de olhos fechados, direito ao cumprimento de seu dever.

Era um idealista, quasi um sonhador.

Ninguem como elle comprehendia a vida e lhe dava valor e, ainda quando tudo lhe parecesse sombrio, sabia descobrir um pedaço de céo azul, um sorriso bom e confortador que lhe augmentava a certeza de que nem tudo estaria perdido emquanto houvesse sobre a terra um pouco de bondade, um pouco de amor.

Era um bom, de uma bondade simples, natural, espontanea.

Quando interno de cirurgia muitas vezes o vimos, carinhoso e sorridente, confortar o doente que havia tratado e com a mesma jovialidade servir de arrimo ao enfermo até o leito.

Com estas qualidades raras, João Eduardo possuia um amigo em cada um que com elle convivesse. Não é de estranhar, pois, a profundeza do golpe que para os seus collegas foi o desapparecimento de João Eduardo Alves de Lima.

Registando o fallecimento do doutorando João Eduardo Alves de Lima a "Revista de Medicina", de quem sempre foi amigo, cumpre o doloroso dever e é ainda sob a magua dessa fatalidade que se associa á grande dor da familia do professor Alves de Lima e de seus companheiros de jornada academica.

\title{
Prof. Henrique Lindenberg
}

A Congregação da Faculdade de Medicina de S. Paulo acaba de prestar mais uma homenagem devida áquelle que foi um dos seus mais illustres membros, collocando sua effigie em bronze numa das salas da clinica oto-rhino-laryngologica da escola. Este é seguramente um dos actos mais justos de quantos da especie hajam emanado daquella corporação.

Embora desapparecido ha ja mais de um anno, não é hoje menos viva a recordação dessa figura inconfundivel, que se chamou Henrique Lindenberg, o qual deixou um claro ainda não preenchido no seio da classe que nobilitava; não é menos intensa a luz que seu vulto ainda projecta sobre os que o rodearam, collegas, discipulos, amigos, que sentem e continuarão a sentir a influencia salutar desse espirito superior, vendo nelle um modelo a imitar, um exemplo a seguir, uma bussola para nortear.

De H. L. pode-se affirmar sem receio de exaggerar que foi uma individualidade insubstituivel. Para a classe medica éra um paradigma de dignidade, com- 
postura, honestidade profissional, e, pela sua estatura moral, impunha-se em todos os terrenos ; pela elevação do seu espirito, era querido dos amigos e respeitado pelos que, por força das circumstancias, militavam em campo adverso, tornando-se por isso muitas vezes elemento apaziguador nos dissidios que, frequentemente, são de lamentar no nosso meio medico.

- Na cathedra, professor que bem comprehendia o seu papel, espirito pratico, intelligente, avesso aos effeitos mirabolantes da oratoria, s6 tinha em mira a aprendizagem real dos alumnos que lhe eram confiados, iniciando-os honestamente nos conhecimentos theoricos e praticos da especialidade, não perdendo as opportunidades que se lhe deparavam de ministrar conselhos e ensinamentos de moral profissional. Rigoroso no exercicio do magisterio, sabia alliar a justiça á bondade e, assim, de cada alumno fazia um amigo respeitoso.

Mestre, que o foi, do brilhante nucleo inicial de otologistas de S. Paulo, ahi revelava-se em toda sua plenitude o homem superior, a alma grande, o coração bonissimo, esforçando-se por attrahir para a especialidade collegas nos quaes lobrigava qualidades, principalmente moraes, procurando insistentemente despertar-lhes o interesse, aguçar-lhes a curiosidade, apontando-lhes as bellezas da materia, dando generosamente tudo que seus estudos e larga experiencia haviam adquirido. Por esta forma fez verdadeiros discipulos e todos reconhecem que foi o professor de S. Paulo que fez escola.

Profissional do maior e mais merecido renome, viu-se em pouco tempo senhor de uma das mais numerosas e selectas clientelas do paiz, pois, não s6 de S. Paulo, como dos Estados mais longinquos acorria gente á procura de Lindenberg, confiante no seu saber e na sua probidade.

Estudioso, observador e investigador, muito poderia ter produzido si os affazeres do magisterio e da clinica, bem assim a sua grande modestia não houvessem impedido o registro de muita materia que o labor dos annos a fio accumulara em sua mente. Entre os seus trabalhos originaes forçoso é lembrar pela importancia nacional do assumpto a notavel memoria que apresentou ao Congresso PanAmericano de Oto-rhino-laryngologia sobre Leishmaniose nasal (Estudo anatomo-pathologico e clinico) que firmou doutrina a respeito.

H. L. encarava o exercicio da medicina de maneira sobremodo séria e escrupulosa : estudava muito e incitava continuamente os seus amigos ao estudo. Recordamos, a proposito, um dos seus mandamentos para o exercicio da profissão, o qual reza : "Clinicar sem estudar é deshonestidade". A sua integridade nunca permittiu que indicasse uma intervenção cirurgica sem que tivesse conviç̧ão plena de que o paciente tiraria da mesma bons resultados, mesmo nos doentes de S. Casa.

Homem crente, obedecia rigorosamente aos preceitos do seu credo, contribuindo com avultado auxilio moral e material para a propagação da fé. Entretanto, senhor da mais fina educação, éra tolerante a respeito, nunca cuidou de impor a sua crença aos que o cercavam, embora intimos; nem uma simples insinuação ; muito menos abriu a bocca para discutir, com quem quer que fosse, assumptos religiosos : respeitava o credo de todos. 
Amigo, éra de uma dedicação invulgar, prompto, immediatamente, a qualquer hora para acudir ao chamado, embora com sacrificio dos seus interesses, e sempre affavel, minucioso ao dispensar os seus cuidados; náo esquecia velhas amizades, procurando-as expontaneamente para auxiliar nas horas de difficuldades ou para encaminhar na vida os que custassem a tomar rumo. Interessavase particularmente pela sorte de estudantes pobres : epoca houve em que custeou a manutenção de seis desses rapazes ao mesmo tempo. Assim valeu a muitos, e muitos lhe devem o bem estar que desfructam. Lindenberg éra um bom.

Chefe de familia exemplarissimo, proporcionava-lhe o maior conforto e consagrava toda sua attenção ao apuro da educação dos seus Filhos.

Esse conjuncto de nobres qualidades, aqui por alto esboçadas, faziam de $\mathrm{H}$. L. uma personalidade prestigiosa na classe que honrava, admirada na sociedade, adorada pelos seus doentes.

H. L. falleceu prematuramente, em 13 de julho de 1928, contando 50 annos de edade, quando, no mais intenso da sua actividade profissional, muito era de esperar ainda delle em beneficio da cultura especializada do nosso meio medico.

Nascido no Estado do Rio e havendo perdido seu progenitor ainda moço, Lindenberg éra o fructo do seu proprio esforço, éra um self made man. Formouse em pharmacia com notas distinctas, na velha escola de Ouro Preto e exerceu essa profissão em S. Paulo. Os seus horizontes não se satisfaziam naquella situação : aspirava ser medico. Depois de 5 annos de trabalho, com algumas economias e muita força de vontade embarcou para os Estados Unidos da A. N. onde fez com brilhantismo o seu curso medico e, terminado este, com o proposito de especializar-se em oto-rhino-laryngologia, encaminhou-se para o velho mundo, onde, principalmente em Vienna, a Meca da especialidade, dedicou-se com tal affinco e enthusiasmo ao estudo que causou admiração aos proprios mestres, entre os quaes Urbantschich, o qual, depois de um anno de estagio, confiou-lhe a chefia interina da sua clinica hospitalar, em uma de suas ausencias temporarias, o que tem muita significação dada a severidade com que essas cousas são encaradas naquellas plagas.

Nessa epoca, exgottado o seu "pé de meia" H. L. teve de levar vida modestissima, mas não esmoreceu e luctou até vencer em toda linha.

De volta á patria, dedicou-se com ardor ao seu mistér; grangeou renome e impoz-se pela sua capacidade entrando desde logo a renovar o ambiente oto-rhino-laryngologico paulista. Iniciou sua actuação na S. C. M. onde reorganizou os serviços da especialidade, dando-lhe feição moderna tornando-os movimentadissimos, graças á sua actividade realizadora, particularmente no terreno cirurgico. Attrahiu para a sua companhia um escolhido grupo de moços aos quaes ensinou e orientou com carinho paternal e que hoje constituem um respeitavel grupo de especialistas.

Lindenberg batia-se pelo augmento do numero de laryngologistas e pela creação de serviços publicos da especialidade. Seria difficil ennumerar aqui as provas do seu desprendimento, tantas são ellas. Seu raio de acção em breve foi se dila- 
tando, estendendo-se principalmente ao Sanatorio Santa Catharina e ao H. Humberto I.

Creada a F. de Medicina de S. Paulo, Arnaldo V. de Carvalho fazendo justiça ao seu valor, chamou-o para reger a cadeira de oto-rhino, onde como todos sabem, deixou uma esteira luminosa da sua passagem.

Dedicando estas palidas linhas á memoria de H. L., Rev. de Med. cumpre egualmente o seu dever, para com o inesquecivel mestre e tambem visa apontalo aos jovens collegas como um magnifico exemplo do poder da força de vontade, do estudo, do trabalho alliado a uma probidade profissional a toda prova.

\section{S. P.}

\section{Professor Lauro Travassos}

Quem se der ao trabalho de compulsar a lista dos brasileiros que se dedicam ao labor scientifico e ao magisterio superior, desde os primordios do movimento intellectual do Brasil até os ultimos annos, encontrará, sem duvida, um nome que sobreleva e resalta com brilho invulgar, quer pela massa, quer pela qualidade da producção.

Será um pioneiro ? Algum -dos que iniciaram no Brasil a era scientifica e, encontrando campo virgem puderam sobresahir á custa da pequena producção existente ? Ou algum vetusto cultor da sciencia, que durante toda uma longa vida de aturado esforço apresente tão farta mésse de producção que se impõe já pela importancia dos themas que atacou, já pela variedade e quantidade do acervo ? Ou alguem que pelas facilidades excepcionaes que encontrou tenha podido constituir em torno de si ambiente por tal forma propicio á realisação de seus designios que tudo convirja em seu auxilio?

Nada d'isso. Seu apparecimento no campo das luctas incruentas da sciencia data de bem pouco tempo : não é um pioneiro ; não teve ainda em seu auxilio o concurso dos annos e sua mocidade é attestada pelo vigor e fecundidade da producção : não é um velho; trabalha no Brasil, onde só excepcionalmente encontra o scientista as facilidades a que tem direito : é um luctador.

Lauro Travassos, nascido a 2 de Julho de 1890 no littoral do Est. do Rio de Janeiro, na cidade de Angra dos Reis, cursou preparatorios no conhecido Collegio Alfredo Gomes, da Capital Federal, matriculando-se em 1907 na Faculdade de Medicina do Rio, onde lhe foi collado o gráo de doutor em medicina em 1912.

Seu pendor pelo estudo das Sciencias Naturaes cedo levou-o a procurar a grande officina scientifica do Brasil, a escola de Oswaldo Cruz, Manguinhos, onde 